\title{
Inaccuracies in using aortic valve gradients alone to grade severity of aortic stenosis
}

\author{
$M$ J GRIFFITH, * CATHERINE CAREY, $\dagger$ D J COLTART, B S JENKINS, \\ $M M$ WEBB-PEPLOE \\ From the Department of Cardiology, St Thomas' Hospital, London
}

SUMMARY The severity of aortic stenosis is an important determinant of prognosis in patients with symptoms who do not undergo valve replacement. To assess the pitfalls of using valve gradients alone 636 patients with aortic stenosis in whom the aortic valve area had been calculated by the Gorlin formula were studied. The correlation between valve area and aortic gradients was poor. No gradient was found that was both sensitive and specific for aortic stenosis. The maximum predictive accuracy was $81 \%$ for a mean gradient of $30 \mathrm{~mm} \mathrm{Hg}$ and $80 \%$ for a peak gradient of 30 $\mathrm{mm} \mathrm{Hg}$. A mean gradient of $50 \mathrm{~mm} \mathrm{Hg}$ or a peak gradient of $60 \mathrm{~mm} \mathrm{Hg}$ were specific with a $90 \%$ or more positive predictive value. It proved difficult, however, to find a lower limit with a $90 \%$ negative predictive value. Patients with severe aortic stenosis and low gradients (peak or mean gradient of $<30 \mathrm{~mm} \mathrm{Hg}$ ) had small ventricles (on both angiographic and echocardiographic data) with good ejection fractions and so were unlikely to be detected subjectively. In comparison patients with mild aortic stenosis and low gradients tended to have more aortic regurgitation but have similar degrees of left ventricular hypertrophy on echocardiographic or electrocardiographic criteria.

The aortic valve area should be measured in all patients with the suspicion of severe aortic stenosis with a mean gradient of $<50 \mathrm{~mm} \mathrm{Hg}(50 \%$ of patients in this study) or a peak gradient of $<60 \mathrm{~mm} \mathrm{Hg}$ (47\% of patients in this study).

The severity of aortic stenosis, as assessed by valve area, is an important determinant of prognosis in patients with symptoms who do not undergo valve replacement.' The widespread use of aortic valve gradients alone, either derived invasively or by Doppler echocardiography, is likely to be an inaccurate way of assessing the severity because it ignores cardiac output. This inaccuracy is increased by the fall in cardiac output as aortic stenosis progresses. ${ }^{2-4}$ Furthermore, patients with low cardiac outputs have a very poor short term prognosis if the valve is not replaced. 5

We studied the inaccuracy of both mean and peak aortic valve gradients alone in predicting aortic valve area and the values of valve gradient at which valve area must be calculated to ensure accurate assessment of the severity of aortic stenosis.

Requests for reprints to Dr M J Griffith, St George's Hospital, London SW 17 ORE.

Present addresses: *St George's Hospital, London SW17 ORE; †The London Hospital, London E1 $1 \mathrm{BB}$.

Accepted for publication 23 May 1989

\section{Patients and methods}

\section{METHODS}

Over a 10 year period 636 consecutive patients with a precatherisation diagnosis of aortic stenosis were studied at St Thomas' Hospital. Patients were catheterised if they had symptoms or if the clinical diagnosis of severe aortic stenosis was made. Because Doppler assessment of the gradient or valve area was not available (or in its development phase), no attempt was made to grade the severity on the basis of the echocardiogram. All patients underwent full left and right heart catheterisation. All had an aortic valve gradient $>10 \mathrm{~mm} \mathrm{Hg}$. Patients with mitral stenosis or > grade I mitral regurgitation were excluded from the study. Cardiac output was calculated by indocyanine green dye dilution. Dye was injected in the pulmonary artery and measurement was made with an earpiece densitometer and dye curve analysis was performed by a Nihon Kohden cardiac output computer. ${ }^{6}$ This was verified by the fore-'n-aft triangle method. ${ }^{7}$ The mean of three measurements was calculated. 
Angiographic volumes were measured by planimetry from the right anterior oblique angiogram. ${ }^{8}$ Intracardiac distances were calibrated by moving the angio table a known distance and using the tip of the pigtail catheter in the left ventricle as the reference point. Extrasystolic or post-extrasystolic beats were excluded and angiographic stroke volume and cardiac output were then calculated by planimetry. The aortic valve gradient was measured by withdrawal of a fluid filled catheter across the valve. In atrial fibrillation simultaneous measurements were obtained with twin lumen catheters and the transseptal approach was used when the aortic valve could not be crossed retrogradely. Peak to peak gradients were measured directly and the mean gradient was measured by computerised planimetric integration, averaged over a minimum of five beats. The systolic ejection period was calculated in the standard manner. The aortic valve area was then calculated with the classic Gorlin formula ${ }^{9}$ based on the green dye cardiac output, unless there was grade 3 or 4 aortic regurgitation, when the angiographic cardiac output was used.

Aortic valve area $\left(\mathrm{cm}^{2}\right)=\frac{\text { valve flow }(\mathrm{ml} / \mathrm{min})}{44.5 \text { mean valve gradient }}$

Electrocardiographic left ventricular hypertrophy was defined as being present if the sum of the $S$ wave in lead V1 and the R wave in lead V5 or V6 was $>35 \mathrm{~mm}^{10}$

One operator performed and reported $90 \%$ of the echocardiograms. The $M$ mode was guided by cross sectional images, using the ATL 300 or the HewlettPackard 7702A machines. The echocardiographic dimensions of the wall and cavity were measured just below the tips of the mitral valve leaflets in the parasternal view. Wall dimensions were measured at the end of diastole.

\section{STATISTICAL ANALYSIS}

Log plots of mean and peak gradients were plotted against the aortic valve area to determine the correlation coefficient. We used logarithmic plots because the relation is not linear. Because of the possibility that lack of correlation was a function of aortic regurgitation this was repeated with the patients divided into subgroups by angiographic grade of aortic regurgitation. Severe aortic stenosis was defined as a valve area of $\leqslant 0.9 \mathrm{~cm}^{2}$ and the sensitivity, specificity, and diagnostic accuracy were calculated for the range of values of aortic valve gradients. Both these functions were performed on the University of London computer by the Statistical Analysis System. Student's $t$ test was used to compare continuous variables and $\chi^{2}$ was used for proportions.
Table 1 Patient details

\begin{tabular}{ll}
\hline Variable & Result \\
\hline Sex & $29 \%$ female \\
Mean (SD) age & $58(11) \mathrm{yr}$ \\
Mean valve area & $0.94(0.71) \mathrm{cm}^{2}$ \\
Peak gradient & $60.3(35) \mathrm{mm} \mathrm{Hg}$ \\
Mean gradient & $50 \cdot 6(25) \mathrm{mm} \mathrm{Hg}$ \\
Mean EF & $57(15) \%$ \\
Mean CI & $3 \cdot 3(1.6) 1 / \mathrm{min}^{2} \mathrm{~m}^{2}$ \\
Mean LVEDI & $95 \cdot 1(45) \mathrm{ml} / \mathrm{m}^{2}$ \\
\hline
\end{tabular}

EF, angiographic ejection fraction; CI, cardiac index; LVEDI, angiographic left ventricular volume index.

\section{Results}

Table 1 summarises the patient details. The aortic valve area was calculated in all patients and the peak gradient was available in 597 patients. The patient population studied had a range of severity of aortic stenosis with a mean aortic valve area of $0.94 \mathrm{~cm}^{2}$. Table 2 shows the details of the patients' symptoms. Nearly all the patients had symptoms $(94 \%)$-with chest pain in $58 \%$ and syncope in $23 \%$. The patients with severe aortic stenosis were significantly more likely to have symptoms and specifically more likely to have chest pain or syncope than those patients with mild aortic stenosis. Figures 1 and 2 show the plots of aortic valve area against mean and peak gradients and figs 3 and 4 show the log plots. There is a wide degree of scatter and this is reflected in the poor correlation seen with $\mathrm{r}$ values of -0.71 and -0.70 for mean and peak gradients respectively calculated by linear regression from the logarithmic plots. There was little difference when the patients were subdivided according to grade of aortic regurgitation (table 3 ). When there was no aortic regurgitation the $r$ value reached -0.78 for the mean gradient.

Table 4 examines the effect of age on the correlation. There was little difference between the various age groups except in the patients aged $>70$ in whom the correlation was much poorer $(0.53$ for mean gradients and 0.43 for peak gradients).

Tables 5 and 6 show the sensitivity and specificity of aortic valve gradients from 20 to $100 \mathrm{~mm} \mathrm{Hg}$ for peak gradients and mean gradients respectively. The maximum predictive accuracy is $81 \%$ for a mean

Table 2 Patients' symptoms in relation to severity of aortic stenosis

\begin{tabular}{lrlrl}
\hline Symptoms & \multicolumn{2}{l}{ Severe stenosis } & \multicolumn{2}{c}{ Mild stenosis } \\
\hline None & $15 / 443$ & $(3 \%)$ & $25 / 217$ & $(12 \%)$ \\
Chest pain & $274 / 443$ & $(62 \%)^{\star}$ & $108 / 217$ & $(50 \%)^{\star}$ \\
Syncope & $129 / 443$ & $(29 \%)^{\star}$ & $27 / 217$ & $(12 \%)^{\star}$ \\
\hline
\end{tabular}

${ }^{\star} \mathrm{p}<0.01$. 


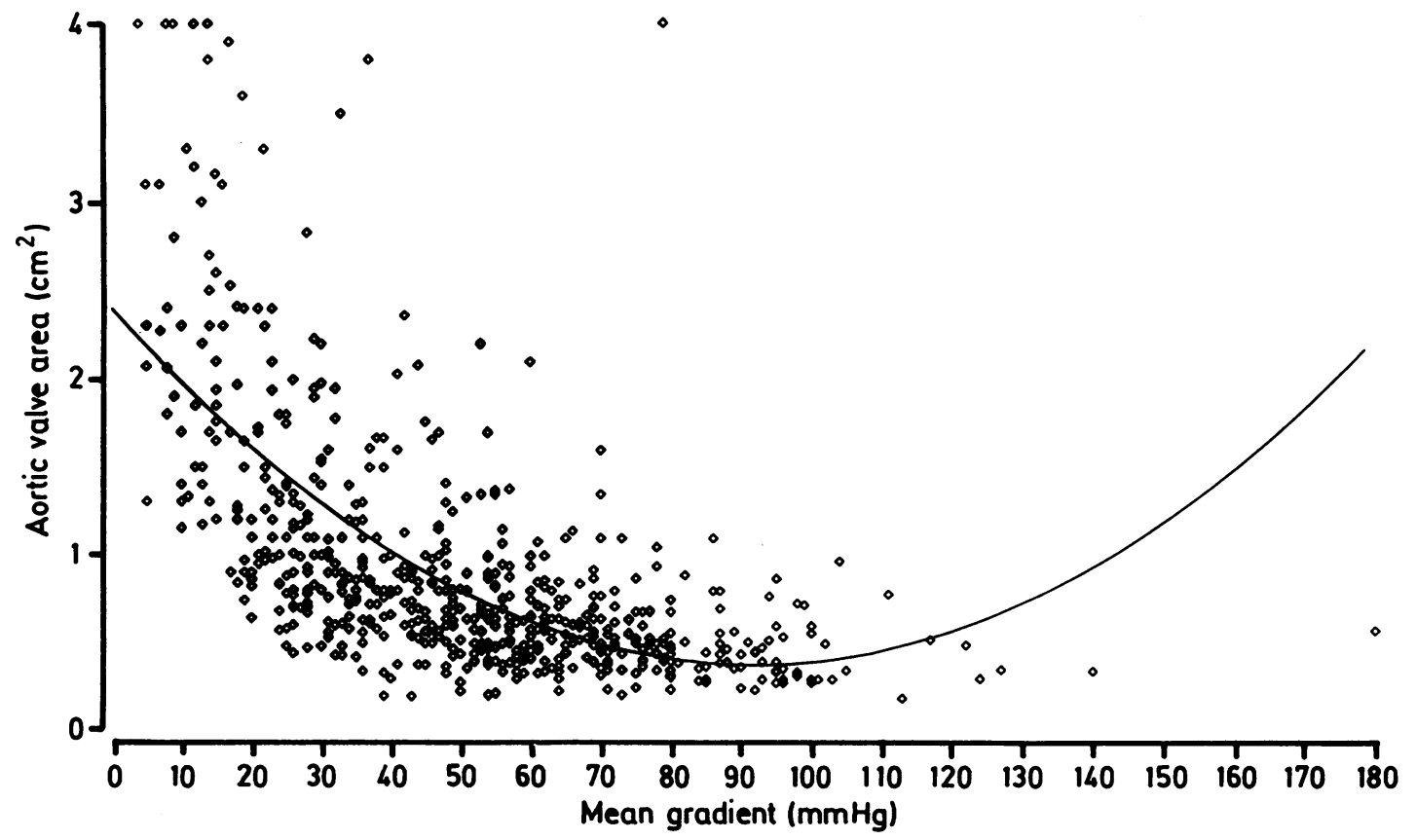

Fig 1 A plot of aortic valve area against mean gradient gave a quadratic regression line.

gradient of $30 \mathrm{~mm} \mathrm{Hg}$ and $80 \%$ for a peak gradient of $30 \mathrm{~mm} \mathrm{Hg}$.

We hoped to establish a range of highly specific or sensitive gradients for clinical use-the upper limit

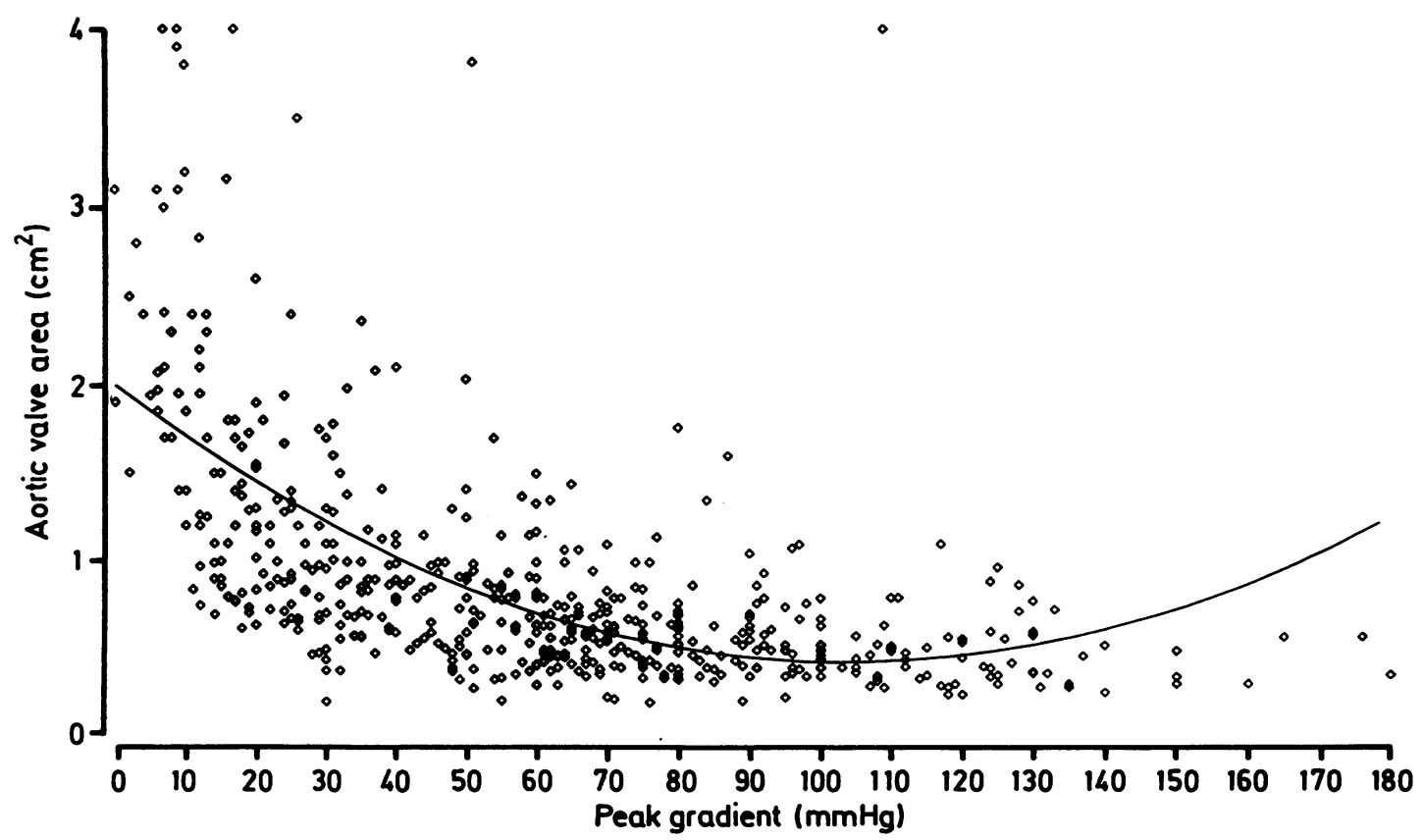

Fig 2 A plot of aortic valve area against peak gradient gave a quadratic regression line. 
Inaccuracies in using aortic valve gradients alone to grade severity of aortic stenosis

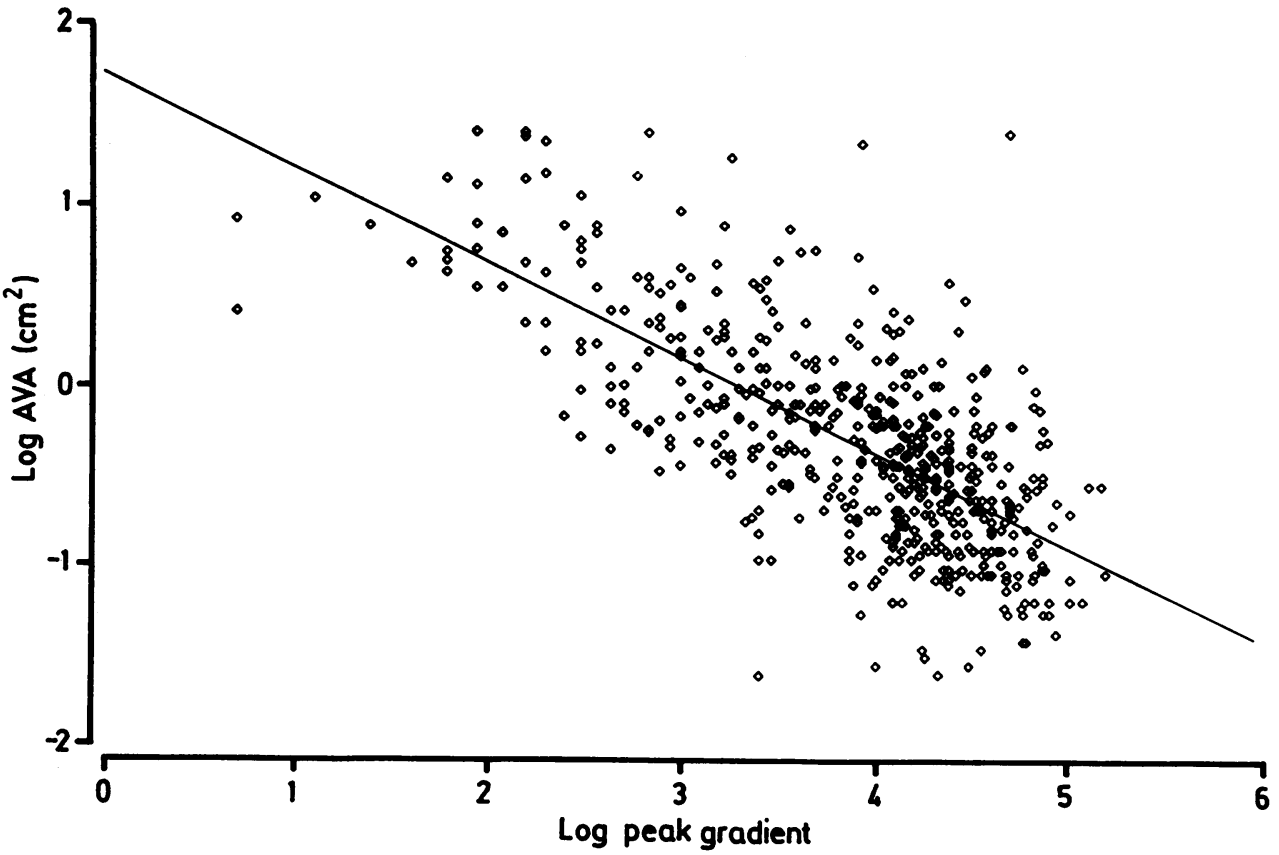

Fig 3 A plot of the natural logarithm of aortic valve area against the peak aortic valve gradient gave a linear regression line.

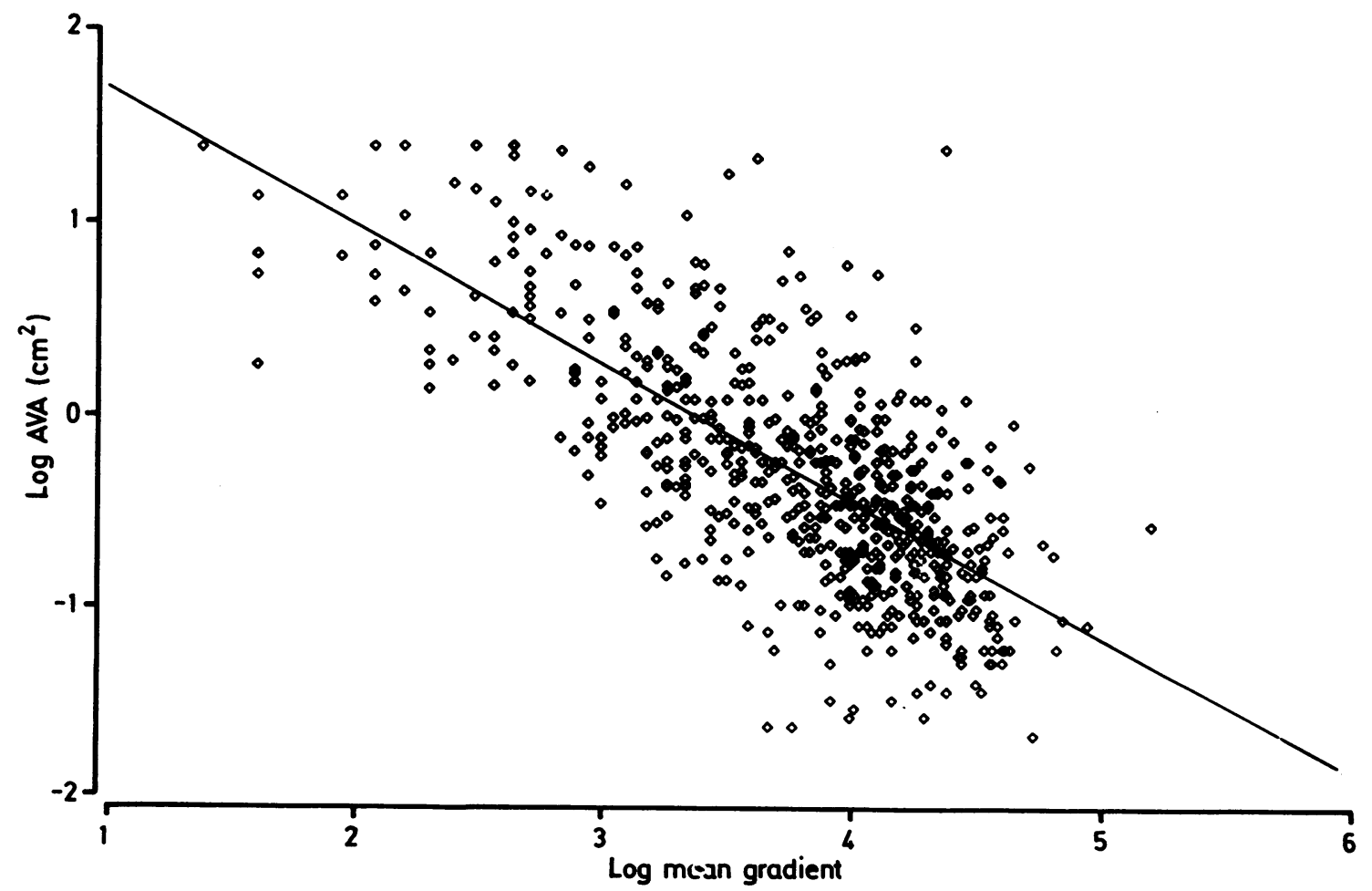

Fig 4 A plot of the logarithm aortic valve area against mean aortic valve gradient gave a linear regression line. 
Table 3 Correlation coefficients for the logarithmic plots of mean and peak gradients and valve area by angiographic grade of aortic regurgitation

\begin{tabular}{llcc}
\hline \multirow{2}{*}{$\begin{array}{l}l \\
\text { Grade }\end{array}$} & \multicolumn{2}{l}{ Aortic valve gradient } & \\
\cline { 2 - 4 } & Peak & Mean & Number \\
\hline 0 & -0.73 & -0.78 & 72 \\
1 & -0.63 & -0.68 & 270 \\
2 & -0.68 & -0.66 & 189 \\
3 & -0.69 & -0.69 & 97 \\
4 & -0.63 & -0.68 & 7 \\
All & -0.70 & -0.71 & 636 \\
\hline
\end{tabular}

$A R$, angiographic grade of aortic regurgitation.

^Number of patients with that grade of aortic regurgitation.

Table 4 Correlation coefficients for the logarithmic plots of mean and peak gradients and valve area by age group of patients

\begin{tabular}{lllc}
\hline & \multicolumn{2}{l}{ Aortic valve gradient } & \\
\cline { 2 - 3 } Age $(y r)$ & Peak & Mean & Number \\
\hline$<40$ & 0.64 & 0.64 & 47 \\
$40-49$ & 0.76 & 0.76 & 87 \\
$50-59$ & 0.69 & 0.70 & 176 \\
$60-69$ & 0.72 & 0.73 & 262 \\
$>70$ & 0.53 & 0.53 & 88 \\
\hline
\end{tabular}
difficult to define a lower limit that correctly clas- $c .$. sified a reasonable number of patients, so we used $\overrightarrow{\vec{F}}$ both $20 \mathrm{~mm} \mathrm{Hg}$ and $30 \mathrm{~mm} \mathrm{Hg}$ for the mean and peak gradients. With these criteria $12 \%$ of patients with a mean gradient $<20 \mathrm{~mm} \mathrm{Hg}$ and $18 \%$ of $\frac{\bar{m}}{\bar{\omega}}$ patients with a peak gradient of $<20 \mathrm{~mm} \mathrm{Hg}$ would $\vec{\sigma}$ be misclassified as having mild aortic stenosis. The $\Omega$ figures increased to $23 \%$ and $30 \%$ respectively when क a lower limit of $30 \mathrm{~mm} \mathrm{Hg}$ was used. These patients $\vec{\circ}$ were looked at in more detail (see table 7). As $\vec{\overrightarrow{ }}$ expected, these patients with low gradients and $\vec{\omega}$ severe stenosis had low cardiac indices and usually had little or no aortic regurgitation, but their ejection fractions were normal with normal end diastolic o volume indices. The ejection fractions were in fact $o$. better than in those patients with mean or peak gradients $<20 \mathrm{~mm} \mathrm{Hg}$ and mild stenosis but the misclassified patients had significantly smaller ventricles by angiographic or echocardiographic estima- $\vec{Z}$ tion $(p<0.05)$. The patients with severe stenosis had less aortic regurgitation. There was no significant difference in left ventricular hypertrophy when determined by either echocardiographic wall dimensions or on electrocardiographic criteria, though $\vec{\bullet}$ there was a trend for patients with mild aortic $\stackrel{\infty}{0}$ stenosis to have more electrocardiographic left ven-

Table 5 Power of peak aortic valve gradients to predict severe aortic stenosis (aortic valve area $<0.9 \mathrm{~cm}^{2}$ ) in 569 patients

\begin{tabular}{|c|c|c|c|c|c|c|}
\hline \multirow{2}{*}{$\begin{array}{l}\text { Gradient } \\
(\mathbf{m m} \mathbf{H g})\end{array}$} & \multirow[b]{2}{*}{ Specificity (\%) } & \multirow[b]{2}{*}{ Sensitivity (\%) } & \multicolumn{2}{|c|}{ Predictive value } & \multirow[b]{2}{*}{ Accuracy $(\%)$} & \multirow{2}{*}{$\begin{array}{l}\text { Number } \\
\text { of } \\
\text { patients }\end{array}$} \\
\hline & & & $+v e(\%)$ & $-v e(\%)$ & & \\
\hline $\begin{array}{l}<20 \\
>\quad 20 \\
>\quad 30 \\
>40 \\
>\quad 50 \\
>60 \\
>70 \\
>\quad 80 \\
>90 \\
>100\end{array}$ & $\begin{array}{l}42 \\
59 \\
72 \\
78 \\
88 \\
92 \\
95 \\
96 \\
98\end{array}$ & $\begin{array}{l}96 \\
89 \\
81 \\
74 \\
64 \\
48 \\
34 \\
27 \\
18\end{array}$ & $\begin{array}{l}79 \\
83 \\
86 \\
88 \\
92 \\
93 \\
93 \\
94 \\
96\end{array}$ & $\begin{array}{l}82 \\
70 \\
62 \\
57 \\
51 \\
44 \\
38 \\
37 \\
34\end{array}$ & $\begin{array}{l}80 \\
80 \\
78 \\
76 \\
71 \\
71 \\
53 \\
48 \\
42\end{array}$ & $\begin{array}{l}89 \\
56 \\
55 \\
38 \\
58 \\
69 \\
60 \\
29 \\
41 \\
74\end{array}$ \\
\hline
\end{tabular}

^Patients with gradients $\geqslant 10 \mathrm{~mm} \mathrm{Hg}$.

Table 6 Power of mean aortic valve gradients to predict severe aortic stenosis (aortic valve area $<0.9 \mathrm{~cm}^{2}$ ) in 636 patients

\begin{tabular}{|c|c|c|c|c|c|c|}
\hline \multirow{2}{*}{$\begin{array}{l}\text { Gradient } \\
\left(m m H_{g}\right)\end{array}$} & \multirow[b]{2}{*}{ Specificity (\%) } & \multirow[b]{2}{*}{ Sensitivity (\%) } & \multicolumn{2}{|c|}{ Predictive value } & \multirow[b]{2}{*}{ Accuracy (\%) } & \multirow{2}{*}{$\begin{array}{l}\text { Number } \\
\text { of } \\
\text { patients }\end{array}$} \\
\hline & & & $+v e(\%)$ & - ve $(\%)$ & & \\
\hline $\begin{array}{l}<20 \\
>\quad 20 \\
>\quad 30 \\
>40 \\
>\quad 50 \\
>60 \\
>\quad 70 \\
>80 \\
>90 \\
>100\end{array}$ & $\begin{array}{r}33 \\
60 \\
73 \\
84 \\
93 \\
97 \\
99 \\
100 \\
100\end{array}$ & $\begin{array}{r}98 \\
92 \\
80 \\
66 \\
46 \\
30 \\
15 \\
9 \\
3\end{array}$ & $\begin{array}{r}75 \\
83 \\
86 \\
90 \\
93 \\
95 \\
97 \\
98 \\
100\end{array}$ & $\begin{array}{l}88 \\
77 \\
63 \\
54 \\
45 \\
40 \\
36 \\
34 \\
33\end{array}$ & $\begin{array}{l}77 \\
81 \\
77 \\
72 \\
61 \\
51 \\
42 \\
38 \\
34\end{array}$ & $\begin{array}{r}77 \\
82 \\
79 \\
83 \\
101 \\
81 \\
67 \\
26 \\
27 \\
13\end{array}$ \\
\hline
\end{tabular}

$\star$ Number of patients with gradients $\geqslant 10 \mathrm{~mm} \mathbf{~ g}$. 
Table 7 Details of patients misclassified when gradients with a $90 \%$ predictive accuracy were used

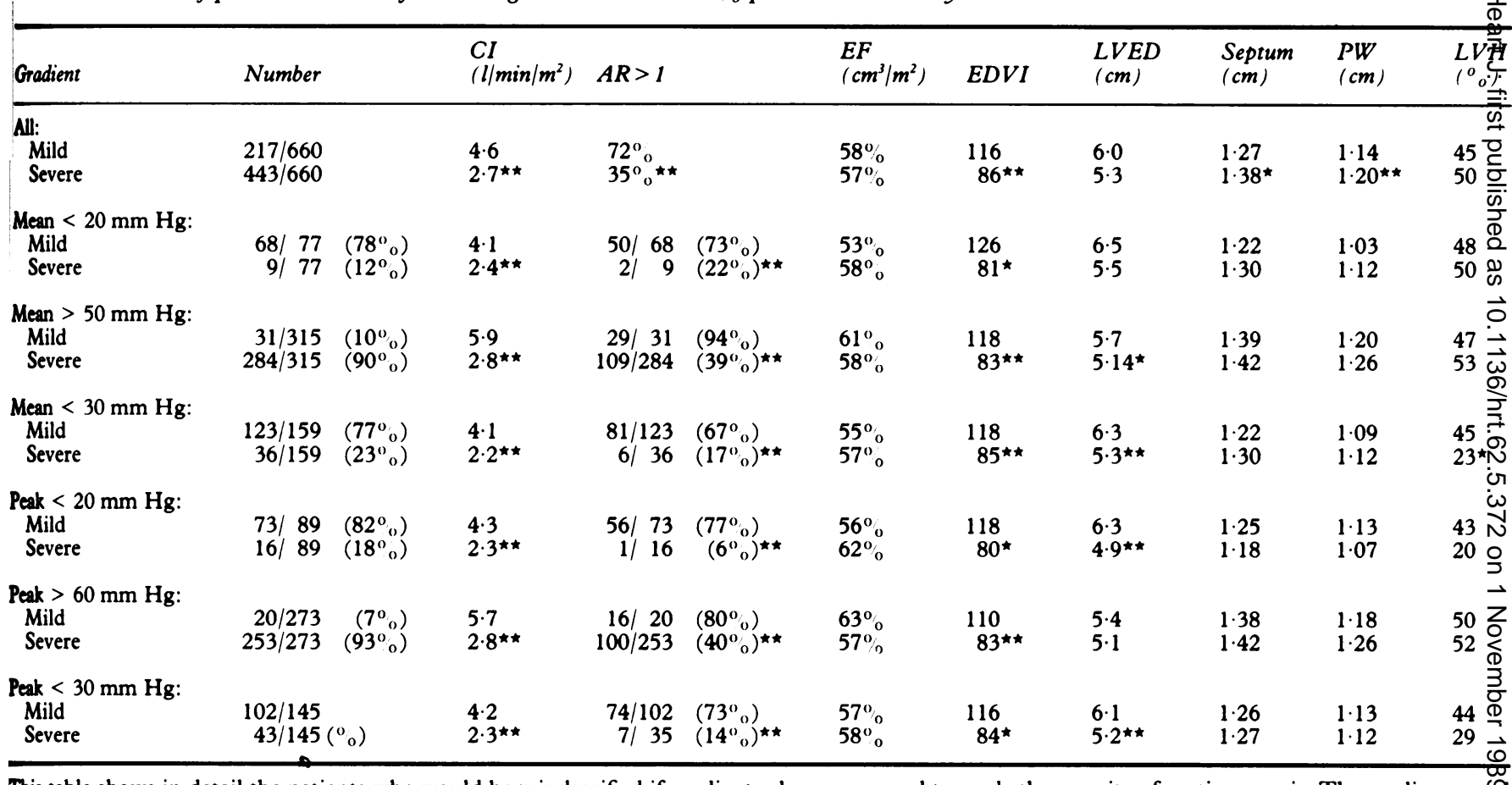

This table shows in detail the patients who would be misclassified if gradients alone were used to grade the severity of aortic stenosis. The gradients used ire the minimum gradient that had a $>90^{\circ}$ o positive predictive value for severe aortic stenosis and the maximum gradient that had a $>90^{\circ}{ }_{0}$ positio predictive value for mild aortic stenosis for both mean and peak gradients. Because no single gradient gave a predictive accuracy of $>90^{\circ}{ }_{0}$ for mild aor $\$ \mathrm{c}$ renosis we used two gradients $(20 \mathrm{~mm} \mathrm{Hg}$ and $30 \mathrm{~mm} \mathrm{Hg}$ ).

$\mathrm{Cl}$, cardiac index; $\mathrm{AR}>1=$ number of patients with greater than angiographic grade 1 aortic regurgitation; EF, angiographic ejection fraction; EDV mgiographic end diastolic volume index; mild, aortic valve area $>0.9 \mathrm{~cm}^{2}$; severe, aortic valve area $\leqslant 0.9 \mathrm{~cm}^{2}$.

${ }^{*}<0.05$ and ${ }^{\star \star} p<0.01$ for comparisons between mild and severe stenosis.

tricular hypertrophy. This difference was significant for mean gradients of $<30 \mathrm{~mm} \mathrm{Hg}$. At $<30 \mathrm{~mm} \mathrm{Hg}$, the peak gradient is more likely to underestimate severity. Body surface area was the same in the two groups.

The higher gradients were more useful because they gave a much lower level of misclassification $\left(10^{\circ}\right.$, for a mean gradient of $>50 \mathrm{~mm} \mathrm{Hg}$ and $7{ }_{0}^{\circ}$ with a peak gradient of $>60 \mathrm{~mm} \mathrm{Hg}$ ). Furthermore, most $\left(94^{\circ}{ }_{0}\right.$ and $\left.78^{\circ}{ }_{0}\right)$ of these patients had $>$ grade 1 aortic regurgitation. The ejection fraction was similar to that in patients with severe aortic stenosis but again these patients had significantly smaller ventricles and there was no difference in echocardiographic wall dimensions or electrocardiographic left ventricular hypertrophy.

Of the patients studied $36^{\circ}$ and $38^{\circ}{ }_{o}$ respectively had intermediate gradients that were neither sensitive or specific enough to be used on their own (peak from $20-60 \mathrm{~mm} \mathrm{Hg}$, mean from $20-50 \mathrm{~mm} \mathrm{Hg}$ ).

\section{Discussion}

An objective measure of the severity of aortic stenosis is important as it is on this basis that the decision for aortic valve replacement is made. If the valve area is accepted as the best measure available then this study shows the inadequacy of using aortic valve gradients alone. Haemodynamic studies of prognosis in severe aortic stenosis have been limited because the effectiveness of aortic valve replacement was demonstrated before modern haemodynamic methods were available. ${ }^{11-13}$ The recent study by Turina and colleagues in patients who refused operation showed that prognosis was best predicted by the valve area. ${ }^{\prime}$ Patients with symptoms and a valve area of $<0.9 \mathrm{~cm}^{2}$ had a poor prognosis while those with a larger valve area with or without symptoms had a good prognosis. Symptom free patients did not have the same poor prognosis; this result is further supported by the study by Kelly and colleagues who found no difference in mortality (excluding the perioperative period) between unoperated patients without symptoms and patients with similar valve areas who had undergone valve replacement. ${ }^{14}$ The importance of the cardiac output was shown by Matthews and colleagues who found that patients with poor left ventricular function and low cardiac output were more likely to die while awaiting valve replacement. ${ }^{5}$ Furthermore, because serial haemodynamic studies showed that as aortic valve disease progresses the cardiac output falls, the use of the gradient alone will 
underestimate the degree of progression. ${ }^{2-4}$ It may be argued that cardiac output is included because even where the valve area is not formally calculated, the decision to operate is also based on the subjective angiographic, echocardiographic, or clinical appearance and is not based on the gradient alone. This study showed that in patients with low gradients those with severe aortic stenosis had similar (or slightly better) ejection fractions and significantly smaller ventricles than those with mild aortic stenosis. These patients would be very difficult to identify on the subjective appearance of the echocardiogram or angiogram and would only be identified if the cardiac output was formally measured. The traditional clues of echocardiographic or electrocardiographic left ventricular hypertrophy would not be helpful because there is no significant difference between patients with severe and mild stenosis and low gradients. The patients with high gradients and mild aortic stenosis nearly all had grade 2 or more aortic regurgitation with large ventricles with good ejection fractions and would be less difficult to identify. In any case, the combination of stenosis and regurgitation in these patients may be sufficient to recommend operation.

It seems illogical to mix objective and subjective measurements when objective evidence can be obtained easily, either invasively or non-invasively. Doppler measurement of the aortic valve area by either the Gorlin formula or a continuity equation correlated closely with invasive measurements. ${ }^{15-17}$ Doppler gradients alone, however, are poor predictors of valve area; the study by Danielsen and colleagues produced very similar correlations to our study. ${ }^{18}$

We suggest the following guidelines for calculating valve areas if a selective policy is envisaged. An upper limit of a mean gradient of $50 \mathrm{~mm} \mathrm{Hg}$ or a peak gradient of $60 \mathrm{~mm} \mathrm{Hg}$ will have a low false positive rate for severe aortic stenosis and most of these patients will have clinically significant aortic regurgitation. We cannot, however, stake an effective lower limit because false negative rates were high for gradients of 20 or $30 \mathrm{~mm} \mathrm{Hg}$, especially where the peak gradient was used. These patients would be difficult to identify if the valve area is not calculated because they have relatively small ventricles with good ejection fractions. We therefore recommend that the aortic valve area should be calculated in all patients with symptoms and aortic stenosis with a mean gradient of $<50 \mathrm{~mm} \mathrm{Hg}(50 \%$ of patients in this study) or a peak gradient of $<60 \mathrm{~mm} \mathrm{Hg}(47 \%$ of patients in this study), particularly if there is no aortic regurgitation.

\section{References}

1 Turina J, Hess O, Sepulcri F, Krayenbuehl HP. $\stackrel{\vec{F}}{+}$ Spontaneous course of aortic valve disease. Eur Heart $\mathrm{O}$ $J$ 1987;8:471-83.

2 Wagner S, Selzer A. Patterns of progression of aortic $\frac{\overline{\bar{F}}}{\overline{\frac{1}{2}}}$ stenosis: a longitudinal haemodynamic study. $\mathbb{D}$ Circulation 1982;65:709-12.

3 Nestico PF, DePace NL, Kimbiris D, et al. Progression कै of isolated aortic stenosis: analysis of 29 patients $\vec{\circ}$ having more than one cardiac catheterization. $\mathrm{Am} \mathrm{J}$ Cardiol 1983;52:1054-8.

4 Bogart DB, Murphy BL, Wong BYS, Pugh DM, Dunn $ᄋ$ MI. Progression of aortic stenosis. Chest 1979;76: 391-6.

5 Matthews AW, Barritt DW, Keen GE, Belsey RH. N Preoperative mortality in aortic stenosis. Br Heart $J \dot{\omega}$ 1974;36:101-3.

6 Robinson PS, Crowther A, Jenkins BS, Webb-Peploe $\circ$ MM, Coltart DJ. A computerized dichromatic earpiece densitometer for the measurement of cardiac $\vec{Z}$ output. Cardiovasc Res 1979;13:420-6.

7 Bradley EC, Barr JW. Fore-'n-aft triangle formula for rapid estimation of area. Am Heart $J$ 1969;78:643-8.

8 Greene DG, Carlisle R, Grant C, Bunnell IL. Estimation of left ventricular volume by one plane cineangiography. Circulation 1967;35:61-9.

9 Gorlin R, Gorlin SG. Hydraulic formula for the cal- 0 culation of the area of the stenotic mitral valve, other $\square$ cardiac valves, and central circulatory shunts. $\mathrm{Am}$ Heart J 1951;41:1-29.

10 Romhilt DW, Estes EH. Point-score system for the ECG diagnosis of left ventricular hypertrophy. $A m$ \% Heart J 1968;75:752-8.

11 Takeda J, Warren R, Holzman D. Prognosis of aortic $\overrightarrow{\vec{P}}$ stenosis. Special reference to indications for operative $\frac{3}{3}$ treatment. Arch Surg 1963;87:931-6.

12 Frank S, Johnson A, Ross J Jr. Natural history of valvular aortic stenosis. Br Heart J 1973;35:41-6.

13 Ross J, Braunwauld E. Aortic stenosis. Circulation 1968;38:V61-7.

14 Kelly TA, Rothbart RM, Cooper CM, Kaiser DL, Smucker ML, Gibson RS. Comparison of outcome of asymptomatic to symptomatic patients older than 20 . years of age with valvular aortic stenosis. $\mathrm{Am} \mathrm{J}$ 윽 Cardiol 1988;61:123-30.

15 Zoghbi WA, Farmer KL, Soto JG, Nelson GN, 은 Quinones MA. Accurate noninvasive quantification $D$ of stenotic aortic valve area by Doppler echocardiography. Circulation 1986;73:452-9.

16 Ohlsson J, Wranne B. Noninvasive assessment of valve or area in patients with aortic stenosis. $\mathbf{~ A m ~ C o l l ~ C a r d i o l ~ N ~}$ 1986;7:501-8.

17 Otto KM, Pearlman AS, Comess KA, Reamer RP, $\omega$ Janko CL, Huntsman LL. Determination of the stenotic valve area in adults using Doppler echocare 6 diography. J Am Coll Cardiol 1986;7:509-17.

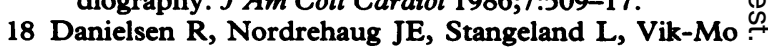
$\mathrm{H}$. Limitations in assessing the severity of aortic $\square$ stenosis by Doppler gradients. Br Heart J 1988;59: 551-5. 